\title{
The Acquired Capability for Lethal Self Injury: Case Studies of Plath's The Bell Jar and Eugenides' The Virgin Suicides
}

\author{
Sepideh Jafari \\ English Department, Faculty of Literature and Foreign Languages, Islamic Azad University Karaj Branch, Iran \\ E-mail: sepidehjafari88.sj@gmail.com \\ Simin Jafari (Corresponding author) \\ Islamic Azad University Karaj Branch, Iran \\ E-mail: jafarisimin54@gmail.com \\ Roghayeh Kiyani Astar \\ Islamic Azad University Ahar Branch, Iran \\ E-mail:ps.mkiyani@gmail.com
}

Received: 19-01-2017

Published: 01-09-2017
Accepted: 10-04-2017

doi:10.7575/aiac.ijalel.v.6n.5p.21
Advance Access Published: July 2017

URL: http://dx.doi.org/10.7575/aiac.ijalel.v.6n.5p.21

\begin{abstract}
Interpersonal theory developed by Joiner (2005) is based on the assumption that people die by suicide because they canacquired capability-and because they want to- desire of suicide. Desire to die arises from two specific psychological states: perceived burdensomeness and thwarted belongingness. The obtained ability of committing suicidal thoughts referred to the second segment of the approach consists of some specific factors, i.e., the person must be capable of doing some lethal activities courageously to put an end to the life; therefore, they present a fearless attitude towards death. Another factor is endurance to face self-injuries pain acquired from the long painful experiences or probably stimulating and motivating situations. In this paper, the researchers intended to present a Joinerian reading of Sylvia Plath's only novel, the Bell Jar, and one of Jeffrey Eugenides' prominent works, the Virgin Suicides. In fact, this qualitative study would analyze the two selected novels (i.e., the Bell Jar and the Virgin Suicides) by the use of the acquired capability for suicide to find out why one takes his/her life by his/her own hands. Based on the findings, Loneliness, social isolation, and thwarted effectiveness can be the mental states that have inflicted an acute pain on the heroines, a pain that makes them ready to die by suicides. Suicidal ideation and witnessing other's suicidal behaviors, habituates the heroines to the concept of death and suicide.
\end{abstract}

Keywords: Acquired Capability, Habituation, Interpersonal Suicide Theory

\section{Introduction}

In order to explain the acquired capability for suicide, Joiner (2005) argues that defining suicide is a very difficult task, indeed, the dictionary definition ( See Merriam Webster Dictionary) could not be clearer- "the act of killing oneself intentionally." This definition seems to apply to many, now, a question may be raised to challenge the subject on the required suicidal factors about the residents of World Trade Center who jumped out of the tower and committed suicide on 9/11. Is it rational to call it suicide? As one searches on the dictionary it can reveal the positive answer based on the explanation on the word "suicide", but according to the New York medical examiner, all September 11 deaths at the World Trade Center were classified as homicides (Joiner, 2005, p. 27). By the logic of the current model, there are two possible answers - those who wished to jump but could not, because they were unable to enact lethal self-injury, and those whose desire to live was enormously strong - enough so to risk intense pain and suffering in exchange for even the smallest chance to live (Joiner, 2005, p. 142). Death by suicide is inherently fearsome, and often involves substantial pain. The obtained ability of suicide is growing more and more by means of frequent painful and/or stimulating situations leads to be accustomed to pain and forget about fear of death. The alternative pieces of research raise some supportive factors to provoke later suicidal behaviors such as motor accidents, non-suicidal self-harm events, prior suicidal attempts, experiencing abuse during childhood, being attacked during the war. Other impulsive behaviors, for example skydiving, intravenous drug use, physical fights, and jumping from high places have also been linked to suicidal behavior. Importantly, provocative behaviors have also been found to be correlated with one's perceived ability to enact lethal self-injury. (Selby, Smith, Bulik, Olmsted, Thornton, McFarlane,... \& Halmi, 2010, p. 2)

Solomon (1980) defines a mechanism approach on the aforementioned adaptation exposure called opponent process theory in line with interpersonal-psychological approach. According to Solomon, the frequent experience of facing the 
issue may abate the impact of previously harmful or challenging motivations such as fear of death and pain due to selfharm. Next step would provoke and support a relief feeling instead of fear, because of repetition. Suicide can be defined as a strong motivation to end one's own life, i.e., it is the triumph over the living powerful enthusiasm, but no one is capable to commit suicide, except they practiced it previously. To obtain the necessary courage required to do deadly self-harm, you need to be involved in a series of painful and stimulus situations in order to adapt fear and pain (Bender, 2011, p. 2). According to opponent-process theory of motivation expanded by Solomon (1980), When a Unconditioned Stimulus (UCS), there are three main emotional occurrences discovered while the people or animals are frequently offered reinforce or intrinsic releaser: (1) emotional or pleasing contrast; (2) an emotional or pleasing adaptation will be increased through regular recurrence (endurance); and (3) a withdrawal or abstinence syndrome arisen from motivating cessation since regular repetition of such provocative issues. In accordance with pleasing qualities of withdrawal or abstinence syndrome, the aforementioned emotional underlying forces develop totally novel stimuli that lead to fresh chances in order to strengthen and reviving operant performances (Solomon, 1980, pp. 1-2). The theory was supported in a study by Solomon and Corbit (1974). In the case of skydivers, the researchers examined the sensation of professional and amateur ones. It was revealed that amateur skydivers experienced less pleasure during the act of landing, but more fear upon diving in comparison with the professional ones; nevertheless, more skydiving experiences led to less fear feeling and more pleasure. The researchers developed a similar investigation with dogs; put them into a Pavlov Harness and made electric shock for 10 seconds. You can consider the shock as motivation of the experiment. Terror and panic sensations overwhelmed the dogs during the first few motivation of the first step. The dogs became watchful and alert after stopping the motivation. Carrying on the experiment with some motivations, the dogs felt happiness and joy rather than the unpleasant sensation after making the shock stopped. One can conclude based on model entitled opponent-process that it is the outcome of an alteration over time from the feeling of fear to pleasure in the fear-pleasure emotion pair. (Solomon, 1980, pp. 12-24)

How does one acquire this ability to surmount the most powerful instinct of nature? The answer, according to the theory proposed here, is through repeated experience with painful or provocative stimuli, especially (but not limited to) deliberate self-harm. As this occurs, people are able to engage in more and more seriously injurious behavior, and may come to view death and related things in peculiarly positive ways (Joiner, 2005, p. 92). Little has been said so far about how potentially suicidal people view death (except that they come not to fear it). When someone is far along the trajectory toward suicide, when they have acquired the ability to enact lethal self-injury, what is their view of death? Though there are very few scientific data on this point, anecdotal and case summary data suggest that people who are near death by suicide view death in a very peculiar way-namely, that death is somehow life giving. (Joiner, 2005, p. 86)

\section{Acquired Capability for Suicide in the Bell Jar}

Esther feels isolated from society and discouraged about her future, when back with her mother, Esther falls into a fatal depression leading to suicide as soon as she was informed that the summer creative writing program rejected her to participate. Joiner (2005) argues that the aforementioned people on the way to suicide describe death as a "beautiful" and "graceful" phenomenon; they sound to merge the notions of death, demolition, and waste with life, livelihood, and care. In the case, someone views death fearlessly; they are able to commit fatal self-harm (p. 123). Esther can incredibly prove this in her speech; she sees death as a relief: "summer calm laid its soothing hand over everything, like death" (Plath, 1963, p. 59). "I crawled between the mattress and the padded bedstead and let the mattress fall across me like a tombstone. It felt dark and safe under there, but the mattress was not heavy enough" (Plath, 1963, p. 64). She feels safe under a tombstone, it seems that she is not afraid of death anymore; moreover, death is a soothing hand and relaxing, and warming mattress is a tombstone for her.

Joiner (2005) argues that there is evidence that social isolation may lead to increases in pain tolerance, just as isolation may lead to the ability to bear increased pain, behaviors that increase the pain threshold may lead to isolation (p. 137).

Esther of The Bell Jar feels isolated and alone and she has never been in a satisfying and stable relationship, the only boy that she loves breaks her heart by cheating her. We can see that her feelings are not just a feeling of loneliness; Esther assumes that she does not belong to anything; her sense of belongingness is totally thwarted. She feels disconnected from everything: "The china-white bedside telephone could have connected me up with things, but there it sat, dumb as a death's head". (Plath, 1963, p. 28)

Joiner mentions in his book that a study of suicidality and family and parental functioning in over 4,000 high school students in Iceland indicated that those adolescents who were well integrated into their families thereby derived protection from suicide ( 2005, p. 125). In other words, isolation from family is very harmful to an adolescent. Esther frankly tells her doctor that she "hates" her mother (Plath, 1963, p. 107), and also she loses her beloved father when she is nine and never overcomes the pain: "I thought how strange it had never occurred to me before that I was only purely happy until I was nine years old" (Plath, 1963, p. 37). One of the main reasons that cause the feeling of loneliness and emptiness in Esther is her father's death, in the time that she really needs him. In fact, she has Oedipus complex, due to the fact she looks for a father substitute in most of the people she encounters with. In other words, one of the main reasons that cause the feeling of loneliness and emptiness in Esther is her father's death, in the time that she really needs him.

Venables, Sellbom, Sourander, Kendler, Joiner, Drislane, ... and Patrick (2015) argue that Lethal acts of self-harm have antecedents - in the form of ideation, planning, and attempts - that are far more common, thus suicide risk can be conceptualized as a behavioral continuum ranging in severity from thoughts about death (e.g., "I wish this all would just 
end" or "I wish I was dead") through contemplation of self-harm to planning and preparation to attempts (p.1). Esther explores several possible ways of committing suicide - using razor blades or a gun, or even drowning. She describes her attempts to drown herself as follows:

"I brought my hands to my breast, ducked my head, and dived, using my hands to push the water aside. The water pressed in on my eardrums and on my heart. I fanned myself down, but before I knew where I was, the water had spat me up into the sun, the world was sparkling all about me like blue and green and yellow semi-precious stones" (Plath, 1963, p. 116).

She plans her suicide repeatedly considering hanging to unleashing her blood in the hot bath. She makes herself ready by suicidal ideation. Finally, Esther decides to end her life by drugs. She hides away in a crawlspace under her home and swallows a bottle of sleeping pills. Fortunately, she is rescued a few days later. Esther would repeatedly ideate and visualize the act of committing suicide and death, eventually she comes to acquire the capability to enact lethal selfinjury, when ideating of the Japanese suicides- disemboweling themselves when anything went wrong- she describes it as a very brave act (Plath, 1963, p. 72). Loneliness and "the black airless sack with no way out" (Plath, 1963, p. 67) in her head, makes herself ready for suicide.

\section{Acquired Capability for Suicide in the Virgin Suicides}

The Virgin Suicides, the story of five sisters, the Lisbons, over the course of an increasingly isolated year and their gruesome deaths is told in the collective voice of their would-be suitors, the neighborhood boys who obsessively watch them, now older but still haunted by the girls' suicides. In this novel, Eugenides (1991) illustrates social isolation, loneliness, and grief. Cecilia has a one sided love to a boy and the only boy that Lux falls in love with abandons her, even their parents have a pathogenic behavior toward them. The mother of the family, Mrs. Lisbon, makes the girls even more aparted from the society by taking them out of school. The suicides start with the youngest sister, Cecilia. She is not successful in her first suicide attempt, but in her second attempt, she achieves what she wants. In addition to her previous suicide attempt, she is lonely and isolated and everyone thinks that she is weird, we can see that in the brief chat that Therese has with the we narrator: "Cecilia was weird, but we're not. We just want to live. If anyone would let us". (Eugenides, 1991, p. 58)

According to joiner, as isolation may lead to the ability to bear increased pain, behaviors that increase the pain threshold may lead to isolation. Provocative behaviors, like self-injury, can be off-putting. These behaviors can also lead others to perceive one as a burden. In one study, a majority of the significant others of those who had recently attempted suicide reported that their support of the patient represented a burden to them. If people who engage in self-harm are ostracized and viewed as a burden because of it, their sense of belongingness may diminish and their sense of perceived burdensomeness may increase. In a number of ways, then, components of the model presented here may feed each other. Any one of the components could be viewed as an entry into a process whereby all three components, and thus high risk for serious suicidal behavior, escalate (p.138). We can see this matter in Cecilia, when everyone thinks she is weird, it's because of her isolation and suicide attempt, even her sisters consider her as a weird person. Cecelia leaves the only party of her short life because, like Esther, she cannot feel anything, she can't feel happiness, she is totally hopeless and alone. In the following example this unfeelingness, isolation, and grief of Cecelia is indicated:

Cecilia fell off the chair and started to become her mother, in the middle of the party. As the last time she spoke, excused with a surprisingly mature voice, while she was playing with her bracelets on the left wrist. Moreover, she looked older and exhausted but still play with the bracelets: "If that's what you want, Cecilia. But we've gone to all this trouble to have a party for you". According to Mrs. Lisbon, Cecilia kept struggling with it until she could unstack it; afterwards she stood still. Mrs. Lisbon asked her to leave the party to upstairs as she went with head down, personal carelessness and suspension, and fixing her beautiful eyes on dilemma of her life that was unknown to the rest. She went upstairs crossed the kitchen and closed the door then walked through the hallway. The downstairs people could hear her footsteps. However, that noise stopped and thirty seconds after that people heard the loud sound of her body jumped down and hit the fence. The witnesses explained that first they heard a sound like the wind concluded that it was from her wedding dress filled with air because of jumping. The heavy human body fell quickly at the pace of rock. It was not important anymore if her brain worked on the way down, or she regretted to commit suicide, or the horrible fence she jumped on; the only significant issue was the fact that her mind did not work nor even exist. (Eugenides, 1991, p. 19)

In above paragraph, Eugenides (1991) articulates Cecilia's feelings and attitudes toward life by which portrays her hopelessness, her suffering, and her inability to feel anything and indicates that she has acquired the ability to commit suicide, her grief is beyond understanding, and she has had another suicide attempt.

The other sister, Mary, does not die in her first suicide attempt, she is alive, but all her sisters have passed away by their group suicide. It seems that she has acquired the capability much more than her sisters, she spends one month very alone, even her parents do not notice that she is still alive. Eventually, she finishes what she started, this time she takes an overdose by swallowing sleeping pills. We can see that the Lisbon girls not only are alone and isolated but also have seen and experienced multiple suicide attempts. They suffer from such an acute pain, that self-injury is nothing compared to that. The real-time monitoring of the narrators can prove that: "Added to their loveliness was a new mysterious suffering, perfectly silent, visible in the blue puffiness beneath their eyes or the way they would sometimes stop in mid stride, look down, and shake their heads as though disagreeing with life. Grief made them wander". (Eugenides, 1991, p.28) 
After Cecilia, the family has been totally ruined, not to mention the girls are not integrated not into their families nor the society. Dines mentions the isolation of the family in his article: when the girls are locked up inside the house after the prom, and Mr. Lisbon is fired, "the house truly died. For as long as Mr. Lisbon had gone back and forth to school, he circulated a thin current of life through the house, bringing the girls treats ... when Mr. Lisbon stopped going out; however, he stopped bringing home sweets". With the firing of Mr. Lisbon, the last contact with the outside world dies. Essentially, no more sweetness or happiness enters the house: "[Mr. Lisbon] looked at the Good Humor truck passing by, the jingle of the bell seemed to trigger a memory, he smiled, or winced - we couldn't tell which - and returned inside". In the end, the house comes to symbolize the decay of the Lisbon girls. Earlier on, "the front door was always left open, because one of the girls was always running in or out". After the prom, Mrs. Lisbon chooses to isolate the girls, and "a cloud always seemed to hover over the Lisbon's roof. There was no explanation, except the psychic one that the house became obscured, because Mrs. Lisbon willed it to be", evidently, the girls end up as prisoners in their own home (2012, pp. 5-6). Dr. Hornicker, the hospital psychiatrist, feels responsible for dealing with the Lisbon cases. He cannot get the girls out of his mind and he writes about them repeatedly. Regarding the fact that the Lisbon girls never speak in the novel and the narrator is a "we", his opinions can help the reader understand the tragic suicides in a better way.

"Dr. Hornicker by citing a recent study by Dr. Judith Weisberg that examined "the bereavement process of adolescents who have lost a sibling by suicide", gave an explanation for the Lisbon girls' erratic behavior - their withdrawal, their sudden fits of emotion or catatonia. The report maintained that because of Cecilia's suicide the surviving Lisbon girls suffered from Post-Traumatic Stress Disorder. "It's not unusual," Dr. Hornicker wrote, "for the sibling of an A.L.S. [adolescent lost to suicide] to act out suicidal behavior in an attempt to come to grips with their grief. There is a high incidence of repetitive suicide in single families". Then, in a marginal aside, he dropped his medical manner and jotted "Lemmings". (Eugenides, 1991, p. 67)

The we narrator (the neighborhood boys) after reading the above lines, go over what they already know, the loneliness and social isolation of the girls: "When we thought of the girls along these lines, it was as feverish creatures, exhaling soupy breath, succumbing day by day in their isolated ward" (Eugenides, 1991, p.68). The parents' pathogenic behavior and family abuse leads to increase in pain tolerance of their children and as earlier mentioned isolation from family really hurts the adolescent. Dr. Hornicker mentions family abuse in the following line: "It was the combination of many factors. With most people, suicide is like Russian roulette. Only one chamber has a bullet. With the Lisbon girls, the gun was loaded. A bullet for family abuse. A bullet for genetic predisposition. A bullet for historical malaise. A bullet for inevitable momentum. The other two bullets are impossible to name, but that doesn't mean the chambers were empty. (Eugenides, 1991, p. 101)

Dines (2012, p.10) argue that in the novel, the perception of suburbia as the place where all the evils of the big city are nonexistent is gone. Suicides used to be a phenomenon related to the cities that is made clear when we are told, "the city newspapers had neglected to report on Cecilia's suicide because of its sheer prosaicness". The reality of the novel is that "the Lisbon girls made suicide familiar". It reminds us of Freud and the theory of uncanny (See Freud, 2003), but with the difference that now the unfamiliar is familiar. The conclusion the boys come to is that "something sick in the heart of the country had infected the girls," and that Cecilia's first attempt at suicide had spread the poison in the air. Poison and sickness are important elements in The Virgin Suicides. The elm tree in front of the Lisbon house is sick, and, seemingly, the entire street or neighborhood is infected. The sickness and the disease can very well be something repressed by all the characters and perhaps by the entire country. Freud (2003) states that repression is very important in connection with the uncanny: "this uncanny is in reality nothing new or alien, but something which is familiar and old-established in the mind which has become alienated from it only through the process of repression" (Freud, 2003, 10). We can see a process of familiarity in the novel, this process starts with the Lisbon girls, they become familiar with suicide, and acquire the ability to commit suicide, by aiding from the theory, and the suicides have become understandable. Now we know that Cecilia's suicide did not spread a poison in the air so that her sisters become infected, the only thing that Cecilia had done was to make her sisters familiar with suicide.

Ribeiro and Joiner (2009) argue that in addition to past suicide attempts serving as a vehicle of increasing the likelihood of engaging in future self-injury, the theory holds that there are other viable pathways of acquiring the capability to engage in lethal self-injury. For example, adolescents who reported engaging in multiple methods of and having a longer history of Non-suicidal Self-injury (NSSI) were found to have the highest rates of past suicide attempts. In addition, individuals who had the longest history of NSSI and reported the least pain during NSSI were approximately two times more likely than others to have attempted suicide in the past were. Even indirect exposure to painful and provocative experiences, such as witnessing others' pain and injury, is hypothesized to increase the acquired capability for suicide (p. 4). The Lisbon girls witness Cecilia's suicide attempts, in her first suicide attempt she slits her wrists during one of her marathon baths, and begins the Lisbon cycle of tragedies. Her second, successful suicide attempt cements the cycle when she jumps onto a spiked fence; Cecilia chooses an extremely brutal way to kill herself. The other Lisbon girl, Lux, plays an important role in the novel. By the middle of Chapter 3, with Cecilia dead, Bonnie, Mary, and Therese are given only collective or passing mention, while Lux emerges as a heroine of singular importance. She has destructive attitudes towards herself, she makes love with anonymous on the roof of the house, but it seems that she does not like it and she does it in winter. The narrators mention that: "It was crazy to make love on the roof at any time, but to make love on the roof in winter suggested derangement, desperation, self-destructiveness far in excess of any pleasure snatched beneath the dripping trees" (Eugenides, 1991, p. 64). We can see that Lux's behavior suggests a will toward self-destruction. 
Another important matter that must be considered can be the heroines' sleeping problems. The girls have sleeping problems after Cecilia, "the Lisbons could hardly wait for night to forget themselves in sleep" (Eugenides, 1991, p. 30). Esther has sleeping problems either; she mentions, "I hadn't washed my hair for three weeks; I hadn't slept for seven nights. My mother told me I must have slept, it was impossible not to sleep in all that time, but if I slept, it was with my eyes wide open, for I had followed the green, luminous course of the second hand and the minute hand and the hour hand of the bedside clock through their circles and semicircles, every night for seven nights, without missing a second, or a minute, or an hour" (Plath, 1963, p. 123).

Nadorff, Fiske, Sperry, Petts, \& Gregg (2013) argue that insomnia symptoms have been found to be positively associated with suicidal ideation among children and adolescents, college students, Veteran, adults and older adults. Although several studies have found that the relation between current insomnia symptoms and suicidal ideation is mediated by depression, one can conclude from some reasons that the above relation is not rational, while believing the fact that insomnia has a direct relationship with suicidal behaviors. Firstly, the study illustrates people with enduring insomnia are six times more likely to improve a major depressive period than the healthy sleepers with no insomnia, signifying that insomnia symptoms may be an important factor in the development of depression and potentially suicidal ideation. In addition, another recent study depicted the positive relationship between insomnia duration and committing suicide apart from the present signs of some factors as insomnia, nightmares, depression, anxiety, and PTSD. Nadorff et al (2013) conclude that findings suggest that insomnia symptoms and nightmares are associated with perceptions of burdensomeness and increased feelings of isolation. Furthermore, sleep problems, as if nightmares may be predictive of suicidal behavior, beyond risk captured within the Joiner's interpersonal-psychological theory of suicide (IPTS) constructs. As previously, stated, the Lisbon girls have the symptoms of post-traumatic stress disorder, we can conclude that symptoms of PTSD, insomnia and depression are associated with suicidal ideation; the presence of insomnia may have both a direct and indirect effect on suicidal ideation. Esther suffers from insomnia and depression either. We can also claim that she also suffers from PTSD, because we can see the symptoms in her for example flashbacks, hopelessness about future, and she still has not overcome the pain of her father's death.

Parental depression is associated with punitive, abdicating, and less supportive parental attitudes and these attitudes would be associated with an increase in adolescent suicide severity. Results indicate that parental depression was associated with adolescent's suicidal thoughts and behavior. Of the three parental attitudes, only parental abdication was associated with the severity of adolescents' suicide ideation and behavior (Hohler, 2015, p. 7). In the case of the Lisbon family, we notice that the parents are suffering from severe mental states especially depression. Mrs. Lisbon has totally quit doing the house work, we can see this matter in the following example: "Already, the house showed signs of uncleanliness, because Mrs. Lisbon had stopped doing laundry or even buying detergent, the girls had taken to washing clothes by hand in the bathtub". (Eugenides, 1991, p. 28)

Mrs. Lisbon is the type of depressed parent that becomes punitive. Forbidding girls from school to "recover" and after that destroying Lux's rock collection, which is very precious to her, are examples of Mrs. Lisbon's worst punishments. In January, as Mr. Lisbon suffered from progressive instability was fired from school as a teacher because of parents' claim that makes the Lisbon house even worse. The family stops leaving the house during the next months, even the grocer did not deliver the weekly products. Mr. Lisbon who was a less supportive parent, and did not stand against his domineering wife, now has become a very abdicating parent: "Mrs. Lisbon once more took charge of the house while Mr. Lisbon receded into a mist” (Eugenides, 1991, pp. 31-32). After their daughters' suicides, the Lisbon couple leaves each other and gets a divorce.

\section{Conclusion}

Joiner (2005) asserts a theory called interpersonal-psychology on suicide illustrated the statement that if someone desires, intends, and has the ability of committing suicide she or he will die by the act. How does one acquire this ability to overcome the most powerful instinct of nature? According to the theory, it is through repeated experience with painful or provocative stimuli, especially (but not limited to) deliberate self-harm. As regards this concept, the acquired capability for suicide- we applied on the novels, we can see that the major characters' mental states are in favor of and consistent with the mentioned theory. Social isolation, loneliness, multiple suicide attempts, suicidal ideation, family abuse and not being integrated into their families are the severe experiences and mental states that the heroines deal with. The psychological pain that they are experiencing, prepares the bed for self-injury and lethal behaviors.

\section{References}

Bender, T. (2011). Impulsivity and Suicidality: The mediating role of painful and provocative experiences. Journal of Affective Disorders, 129, 301-307.

Dines, M. (2012). Suburban gothic and the ethnic uncanny in Jeffrey Eugenides's The virgin suicides. Journal of American Studies, 46 (04), 959-975.

Eugenides, J. (1991). The virgin suicides. New York: Farrar, Straus, and Giroux plc.

Freud, S. (2003). The uncanny. UK, London: Penguin.

Hohler, A. (2015). Parental Depression and the Severity of Adolescent Suicide Ideation and Behavior: A Test of a Mediation Model (Doctoral dissertation, University of Delaware). 
Joiner, T. E. (2005). Why people die by suicide. Cambridge: Harvard UP.

Nadorff, M. R., Fiske, A., Sperry, J. A., Petts, R., \& Gregg, J. J. (2013). Insomnia symptoms, nightmares, and suicidal ideation in older adults. The Journals of Gerontology Series B: Psychological Sciences and Social Sciences, 68(2), 145-152.

Plath, S. (1963). The Bell Jar. New York: Heinemann Plc.

Ribeiro, J. D., \& Joiner, T. E. (2009). The interpersonal-psychological theory of suicidal behavior: current status and future directions. Journal of clinical psychology, 65(12), 1291-1299.

Selby, E. A., Smith, A. R., Bulik, C. M., Olmsted, M. P., Thornton, L., McFarlane, T. L., ... \& Halmi, K. A. (2010). Habitual starvation and provocative behaviors: two potential routes to extreme suicidal behavior in anorexia nervosa. Behavior Research and Therapy, 48(7), 634-645.

Venables, N. C., Sellbom, M., Sourander, A., Kendler, K. S., Joiner, T. E., Drislane, L. E., ... \& Patrick, C. J. (2015). Separate and interactive contributions of weak inhibitory control and threat sensitivity to prediction of suicide risk. Psychiatry research, 226(2), 461-466.Solomon, R. L. (1980). The opponent-process theory of acquired motivation: the costs of pleasure and the benefits of pain. American psychologist, 35(8), 691. 